\title{
Mutants for rice storage proteins. IV. Maternally inherited mutants for storage proteins of protein bodies in the starchy endosperm
}

\author{
Toshihiro Kumamaru, $\ddagger$ \\ Hikaru Satoh,* \\ Takeshi Omura and \\ Masahiro Ogawa $\dagger$
}

Plant Breeding Laboratory, Faculty of Agriculture, Kyushu University, Hakozaki, Fukuoka 812, Japan. * Institute of Genetic Resources, Faculty of Agriculture, Kyushu University, Hakozaki, Fukuoka 812, Japan.

$\dagger$ The Research Institute for Food Science, Kyoto University, Uji, Kyoto 611, Japan.

Maternal inheritance, a phenomenon extremely rare in plants, was observed in two mutants for rice storage protein in the starchy endosperm. When these mutants, 10/13a-L and 10/16-H, were crossed reciprocally with their original variety, Kinmaze, the $F_{1}$ seeds in all crosses showed the same character as the maternal parent. The $F_{2}$ seeds of the reciprocal crosses between $\mathrm{Kinmaze}$ and $10 / 13 \mathrm{a}-\mathrm{L}$ were also of normal type, but those between Kinmaze and 10/16-H showed 10/16-H type. In 10/13a-L, the segregation ratio of $F_{2}$ plants observed in $F_{3}$ seeds showed a good fit to the expected 3:1 ratio, and in 10/16-H, the segregation ratio of $F_{2}$ plants observed in $F_{3}$ seeds showed a good fit to the expected 1:3 ratio. From the results of $F_{1}, F_{2}$ and $F_{3}$ seeds, it was concluded that the mutants were expressed according to the genetic behaviour of material inheritance governed by plant genotype, and that 10/13a-L and 10/16-H were controlled by a single recessive and dominant gene, respectively. SDS-PAGE analysis indicated that both mutant genes were regulatory genes for the storage proteins. Based on the results of allelism tests, the genes for 10/13a-L and 10/16-H were designated as esp-3 and Esp-4, respectively. Since esp-1, the gene controlling the $13 \mathrm{~b}-\mathrm{L}$, a mutant of rice storage protein, produces loss of the effect of maternal inheritance of esp-3, it is assumed that esp-1 is epistatic to esp-3.

\section{INTRODUCTION}

The improvement of rice storage proteins is important for the Asian diet. Studies on rice, however, have generally been limited to ways of increasing the total content of storage proteins (Beachell et al., 1972; Higashi et al., 1974; Kambayashi et al., 1984; Osone and Takagi, 1970) or increasing the lysine content in the storage proteins (Shin et al., 1977). However, due to the fact that the gene(s) for rice storage proteins themselves has never been identified, the qualitative improvement of the rice proteins themselves remains virtually unexplored.

Rice storage proteins are accumulated in two types of protein bodies in the starchy endosperm (Tanaka et al., 1980). Rice prolamin is stored in protein body type I (PB-I), which are spherical proteinaceous particles of lamellar structure, 1-

\footnotetext{
¥ Present address: Plant Breeding and Genetics Research Laboratory, Japan Tobacco Inc., Higashibara, Toyoda, Iwata, Shizuoka 438, Japan.
}

$2 \mu \mathrm{m}$ in diameter. Rice glutelin is deposited in protein body type II (PB-II), a uniformly electron dense structure, $2-3 \mu \mathrm{m}$ in diameter. In SDSPAGE analysis, PB-I shows $10 \mathrm{kDa}, 13 \mathrm{a}, 13 \mathrm{~b}$ and $16 \mathrm{kDa}$ polypeptides; and PB-II shows $22-23 \mathrm{kDa}$, $26 \mathrm{kDa}$ and 37-39 kDa polypeptides (Ogawa et al., 1987; Tanaka et al., 1980; Yamagata et al., 1982).

Since PB-I is hard to digest by humans, whereas PB-II is easily digestible (Ogawa et al., 1987; Tanaka et al., 1975a,b), PB-I is regarded as nutritionally inferior to PB-II. Hence, to improve the nutritional value of the endosperm storage proteins, it is desirable either to increase PB-II content and/or to decrease PB-I.

In a previous paper, we reported four types of mutants for rice storage protein showing (1) $13 \mathrm{~b}$ polypeptide low; (2) $10 \mathrm{kDa}$ and $16 \mathrm{kDa}$ polypeptide high and 13b polypeptide low; (3) $10 \mathrm{kDa}$ and 13a polypeptide low; (4) $57 \mathrm{kDa}$ polypeptide high. These mutants were named $13 \mathrm{~b}-\mathrm{L}, 10 / 16-\mathrm{H}$, 10/13a- L and 57-H, respectively. Mutant lines CM 
21 and CM 1834, which were 13b-L and 10/16-H, respectively, had an increased glutelin content (Kumamaru et al., 1988). It has been shown that 13b-L in CM 21, 10/16-H in CM 1834 and 10/13a$\mathrm{L}$ in mutant line CM 1675 are the mutants for the polypeptides in PB-I (Ogawa et al., 1989). To evaluate their genetic potential for the improvement of rice storage protein, it is necessary to determine the genetic behaviour of these mutant polypeptides. Thus far, experiments done on $13 \mathrm{~b}-\mathrm{L}$ in CM 21 and 57-H in CM 1787 have demonstrated that each of the mutants was controlled by a single recessive gene, which was a mutant of the regulatory gene for the polypeptides in the protein body, and these genes for $13 \mathrm{~b}-\mathrm{L}$ and $57-\mathrm{H}$ were designated as esp (endosperm storage protein)-1 and esp-2, respectively (Kumamaru et al., 1987). The present study further deals with the genetic behaviour of the mutant genes for the polypeptides in CM 1675 and CM 1834.

\section{MATERIALS AND METHODS}

\section{Materials}

Four mutant lines for seed storage protein, CM 21, CM 1787, CM 1675 and CM 1834, were used in these experiments. They were induced by $N$ methyl- $N$-nitrosourea (MNU) from rice cultivar, Kinmaze, as reported elsewhere (Satoh and Omura, 1979), and have been maintained at the Plant Breeding Laboratory, Kyushu University. Fig. 1 and fig. 3 show the SDS-PAGE of the proteins in CM 1675 and CM 1834, respectively, which deal with the genetic behaviour in this work, and Kinmaze. In Kinmaze, the intensity of 13 a (a larger component of $13 \mathrm{kDa}$ ) and $13 \mathrm{~b}$ (a smaller component of $13 \mathrm{kDa}$ ) were almost equal. But the intensity of the 13a polypeptide band was lower than that of the $13 \mathrm{~b}$ polypeptide band in CM 1675 , while the pattern of intensities was reversed in CM 1834. In CM 1675, the intensity of the $10 \mathrm{kDa}$ polypeptide band was lower than that of Kinmaze. In CM 1834, the intensity of the 10 and $16 \mathrm{kDa}$ polypeptide bands was higher than those of Kinmaze. So, the mutant type in CM 1675 and CM 1834 was named $10 / 13 \mathrm{a}-\mathrm{L}$ and $10 / 16-\mathrm{H}$, respectively (Kumamaru et al., 1988).

\section{Crosses}

To investigate the genetic behaviour of the mutant polypeptides in CM 1675 and CM 1834, reciprocal crosses were made between CM 1675 and $\mathrm{CM}$ 1834 , and Kinmaze. The proteins of $F_{1}, F_{2}$ and $F_{3}$ seeds of each cross were analyzed by sodium dodecyle sulfate-polyacrylamide gel electrophoresis (SDS-PAGE).

To test allelism, crosses between mutant lines were made and $F_{1}, F_{2}$ and $F_{3}$ seeds were subjected to SDS-PAGE analysis.

\section{Protein extraction}

Individual rice seed was crushed with pliers, and the tissue was placed in a micro test tube $(1.5 \mathrm{ml})$ with $700 \mu \mathrm{l}$ of $0.125 \mathrm{M}$ Tris- $\mathrm{HCl} p \mathrm{H} 6.8$ containing 4 per cent SDS, $6 \mathrm{M}$ urea, 5 per cent 2-mercaptoethanol and 20 per cent glycerin and incubated at $30^{\circ} \mathrm{C}$ for 4 hours. After centrifugation $(5 \mathrm{~min}$, 15,000 r.p.m.), the supernatants were applied to SDS-PAGE.

\section{SDS-PAGE}

Extracted storage proteins of rice seeds were electrophoresed using the discontinuous buffer system of Laemmli (1970) on a slab gel, and were stained by 0.05 per cent Coomassie brilliant blue R-250 in 7 per cent acetic acid and 50 per cent methanol, and destained by 7 per cent acetic acid and 25 per cent methanol.

\section{RESULTS AND DISCUSSION}

Fig. 1 shows the SDS-PAGE of the proteins of $F_{1}$ and $F_{2}$ seeds from the reciprocal crosses between Kinmaze and CM 1675. In the cross between Kinmaze ( $q$ ) and CM $1675(\circlearrowleft)$, the SDS-PAGE pattern of $F_{1}$ seed proteins showed the normal type, i.e., the Kinmaze type $\left(\mathrm{F}_{1}-1\right)$. In the cross between $\mathrm{CM}$ $1675(+)$ and Kinmaze ( $\delta)$, the SDS-PAGE pattern of $F_{1}$ seed proteins showed the 10/13a-L type, i.e., the CM 1675 type $\left(F_{1}-2\right)$. The SDS-PAGE pattern of $F_{2}$ seed proteins obtained from the reciprocal crosses showed the normal type. From the expression of the character of seed parents in $F_{1}$ seeds, it is assumed that the expression of $10 / 13 \mathrm{a}-\mathrm{L}$ is dependent on either the genotype of the plant, or the cytoplasm. The results of $F_{2}$ seeds indicate that the expression of the mutant is dependent on the former. This led us to speculate that the genotype of the $F_{1}$ plant is heterozygous for $10 / 13 \mathrm{a}-\mathrm{L}$ and, from the results of $F_{2}$ seeds, that $10 / 13 \mathrm{a}-\mathrm{L}$ is recessive to the normal type.

In order to confirm the above supposition, $F_{2}$ plants were cultivated, and the protein of a group of single $F_{3}$ seed per $F_{2}$ plant was analyzed by SDS-PAGE, the results of which are shown in fig. 


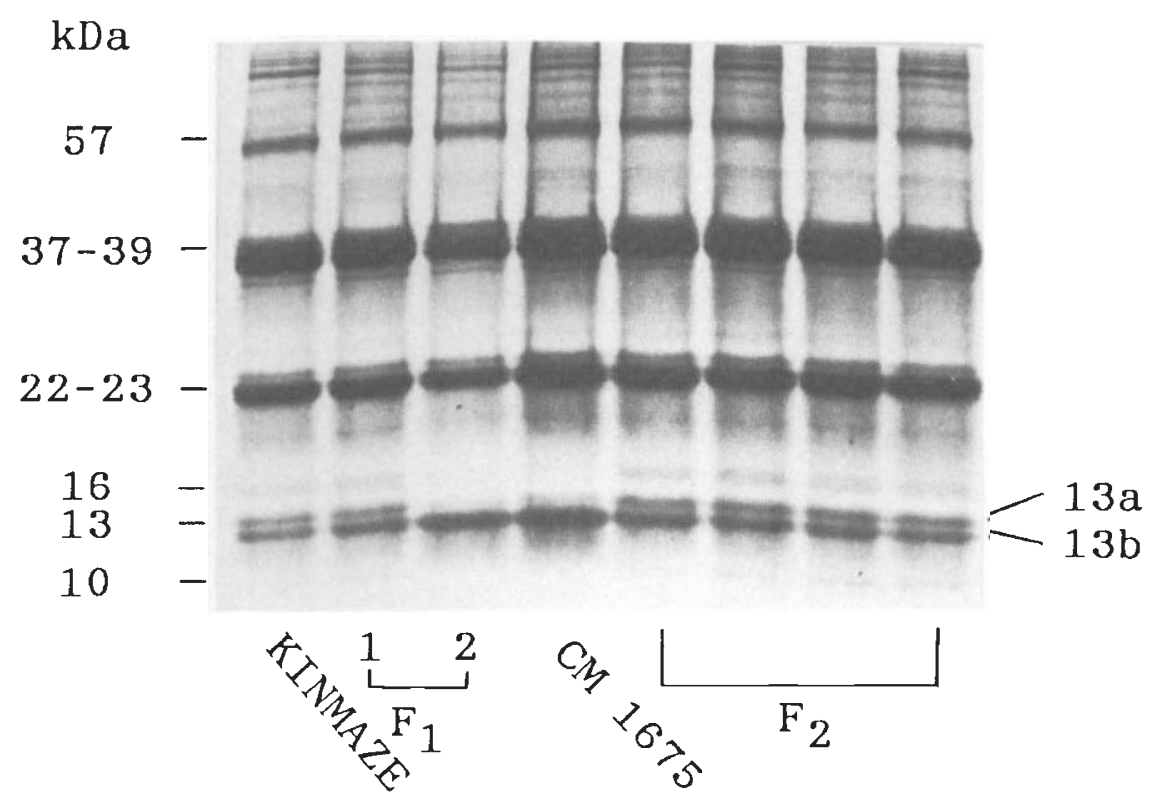

Figure 1 SDS-PAGE analysis of the storage protein in $F_{1}$ and $F_{2}$ seeds of the cross between Kinmaze and $C M$ 1675. ( $\left.F_{1}-1\right) F_{1}$ seed of the cross between Kinmaze $(q)$ and CM $1675(\delta) .\left(F_{1}-2\right) F_{1}$ seed of the cross between CM 1675 ( $\left.q\right)$ and Kinmaze $(\delta)$.

2. Normal and 10/13a- $\mathrm{L}$ types were segregated in the $F_{3}$ seeds. Moreover, in the $F_{3}$ seeds, there was no segregation of individual $F_{2}$ plants (data not shown). These findings suggested that $10 / 13 \mathrm{a}-\mathrm{L}$ in CM 1675 is determined by the genotype of the plant, not the endosperm. In the cross between CM 1675 and Kinmaze, the segregation mode in
$F_{2}$ plants investigated by $F_{3}$ seeds are shown in table 1. The segregation ratio of normal and 10/13a-L types showed a good fit to the expected $3: 1$ ratio. These results suggest that $10 / 13 \mathrm{a}-\mathrm{L}$ in CM 1675 is controlled by a single recessive gene. Fig. 3 shows the SDS-PAGE of the proteins of $F_{1}$ and $F_{2}$ seeds from the reciprocal crosses between

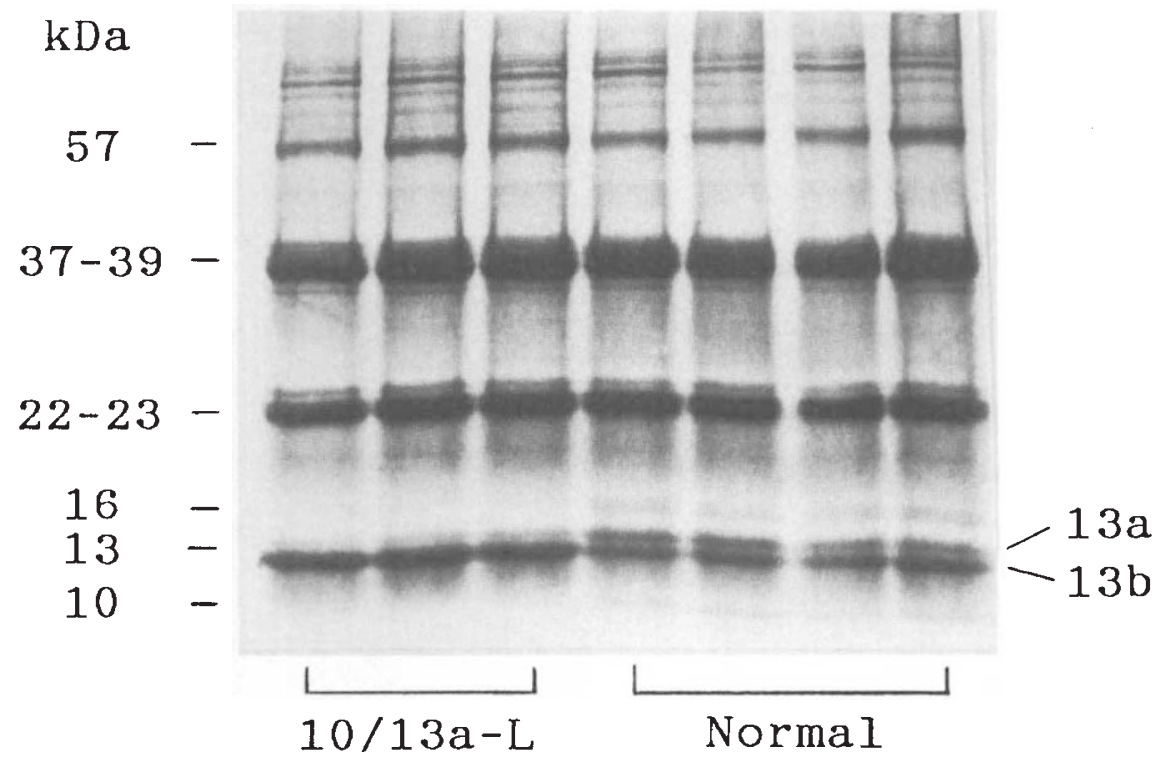

Figure 2 SDS-PAGE analysis of the storage protein in a group of single $F_{3}$ seed per $F_{2}$ plant of the cross between Kinmaze and CM 1675. 
Table 1 The phenotype of $F_{1}$ and $F_{2}$ seeds, and segregation of normal and 10/13a-L types in $F_{2}$ plants as seen in $F_{3}$ seeds of the reciprocal cross between Kinmaze and CM 1675

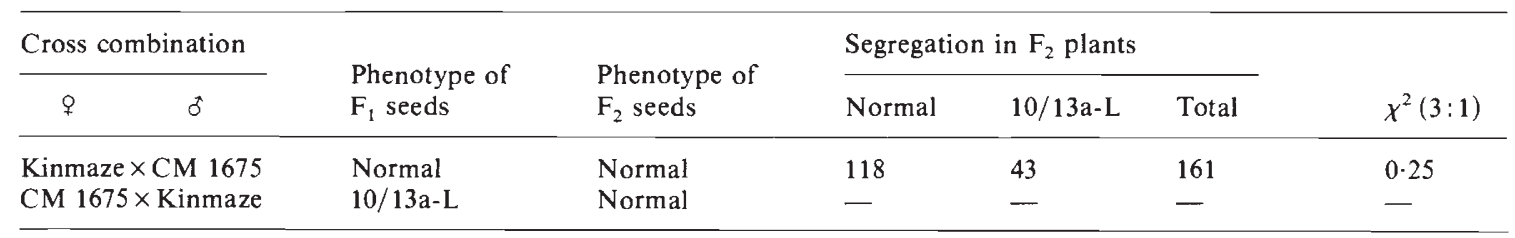

$\ldots=$ No data.

Kinmaze and CM 1834. In the cross between Kinmaze ( $q$ ) and CM 1834 ( $\delta), F_{1}$ seed showed the normal type $\left(\mathrm{F}_{1}-2\right)$, and in the cross between $\mathrm{CM}$ $1834(q)$ and Kinmaze $(\delta), F_{1}$ seed showed the 10/16-H type, i.e., the CM 1834 type $\left(F_{1}-2\right)$. All $\mathrm{F}_{2}$ seeds of the reciprocal crosses showed the $10 / 16-\mathrm{H}$ type. If the $10 / 16-\mathrm{H}$ in CM 1834 is determined by the genotype of the plant, such as $10 / 13 \mathrm{a}-$

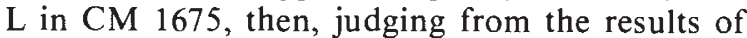
$F_{2}$ seeds, it would seem that the $10 / 16-\mathrm{H}$ is dominant to the normal type.

Fig. 4 shows the SDS-PAGE of the proteins of $\mathrm{F}_{3}$ seeds from the cross between Kinmaze and CM 1834. Normal and 10/16-H types were segregated in the $\mathrm{F}_{3}$ seeds. Since there was no segregation in the $F_{3}$ seeds of individual $F_{2}$ plants (data not shown), it is thought that $10 / 16-\mathrm{H}$ in CM 1834 is also determined by the genotype of the plant. The segregation mode in $F_{2}$ plants investigated by $F_{3}$ seeds from this cross is shown in table 2. The segregation ratio of normal and $10 / 16-\mathrm{H}$ types showed a good fit to the expected $1: 3$ ratio. The results suggest that $10 / 16-\mathrm{H}$ in CM 1834 is controlled by a single dominant gene.

The above genetic phenomenon, in which the character of the endosperm is controlled by plant genotype, is known as "maternal inheritance". This phenomenon, which is extremely rare in plants, has been observed in a few cases such as the egg colour (Uda, 1923) and maternal chocolate mutant (Yoshimura, 1981; 1985) in silkworm.

Gene dosage effect has been reported to occur in $F_{1}$ and $F_{2}$ seed storage protein in barley (Doll, 1980), wheat (Burnouf et al., 1983; Dhaliwal, 1977) and maize (Soave et al., 1981; Valentini et al., 1979). In the case of mutants for the structural genes encoding polypeptides, the gene dosage effect, if any, should appear in the polypeptides of $F_{1}$ and $F_{2}$ seeds. esp-1 and esp- 2 which are genes for 13b-L in CM 21 and 57-H in CM 1787, respec-

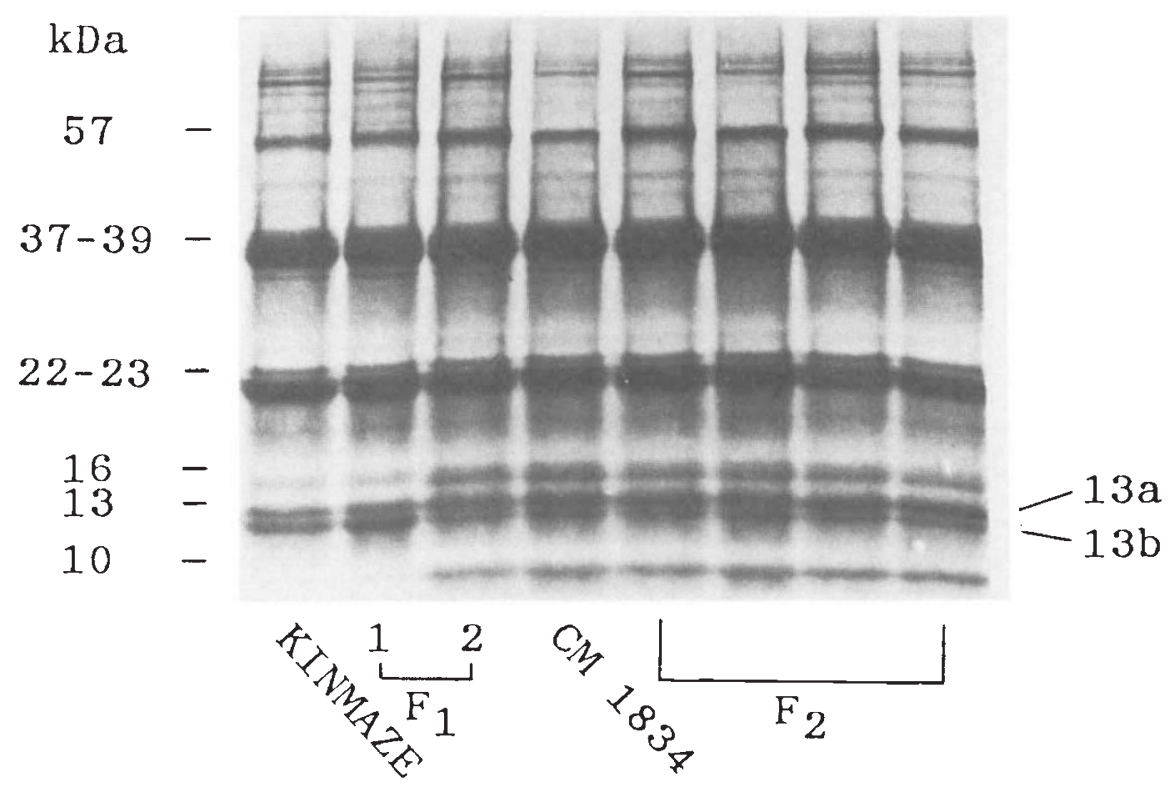

Figure 3 SDS-PAGE analysis of the storage protein in $F_{1}$ and $F_{2}$ seeds of the cross between Kinmaze and $C M 1834$. $\left(F_{1}-1\right) F_{1}$ seed of the cross between Kinmaze $(q)$ and CM $1675\left(\delta^{*}\right) .\left(F_{1}-2\right) F_{1}$ seed of the cross between CM 1675 $(q)$ and Kinmaze $\left(\delta^{*}\right)$. 


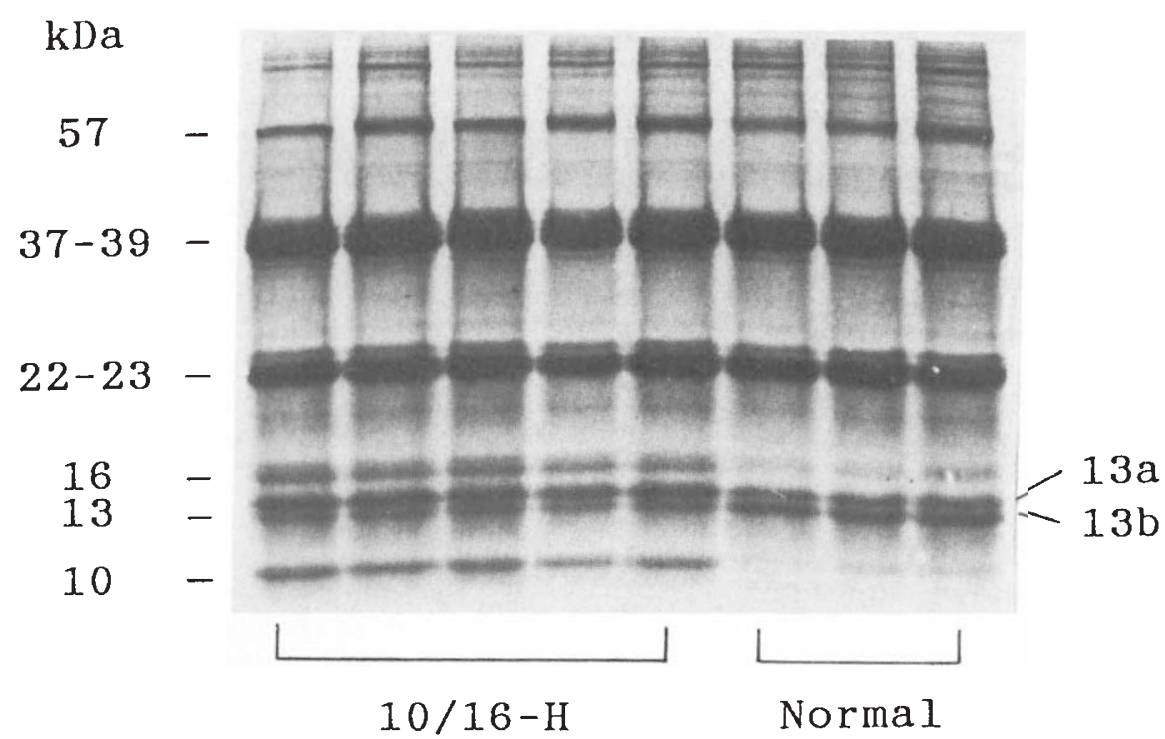

Figure 4 SDS-PAGE analysis of the storage protein in a group of single $F_{3}$ seed per $F_{2}$ plant of the cross between Kinmaze and CM 1834.

tively, are regarded as mutants for regulatory genes of the polypeptides, for they showed no gene dosage effect of this type (Kumamaru et al., 1987). Since the genes for $10 / 13 \mathrm{a}-\mathrm{L}$ and $10 / 16-\mathrm{H}$ also revealed no such gene dosage effect, and since the mutated polypeptides were inherited together (figs. 2 and 4 ), it is likely that the genes are mutations of the regulatory gene for the polypeptides, and are analogous to the cases of esp-1 and esp-2.
To test allelism in the genes for $10 / 13 \mathrm{a}-\mathrm{L}$ and 10/16-H, reciprocal crosses were made of CM 1675 and CM 1834 with CM 21 (esp-1) and CM 1787 (esp-2). The results of SDS-PAGE analysis of $F_{1}$ seeds are shown in table 3 . In cases where CM 21 and CM 1787 were used as the seed parent, all seeds indicated normal type. This suggests that the genes for both $10 / 13 \mathrm{a}-\mathrm{L}$ and $10 / 16-\mathrm{H}$ are located at different locus from esp-1 and esp-2. In order

Table 2 The phenotype of $F_{1}$ and $F_{2}$ seeds, and segregation of normal and 10/16- $\mathrm{H}$ types in $F_{2}$ plants as seen in $F_{3}$ seeds of the reciprocal cross between Kinmaze and CM 1834

\begin{tabular}{|c|c|c|c|c|c|c|}
\hline Cross combination & \multirow{2}{*}{$\begin{array}{l}\text { Phenotype of } \\
F_{1} \text { seeds }\end{array}$} & \multirow{2}{*}{$\begin{array}{l}\text { Phenotype of } \\
F_{2} \text { seeds }\end{array}$} & \multicolumn{3}{|c|}{ Segregation in $F_{2}$ Plants } & \multirow[b]{2}{*}{$\chi^{2}(1: 3)$} \\
\hline$\delta$ & & & Normal & $10 / 16-\mathrm{H}$ & Total & \\
\hline Kinmaze $\times$ CM 1834 & Normal & $10 / 16-\mathrm{H}$ & 39 & 120 & 159 & 0.02 \\
\hline CM $1834 \times$ Kinmaze & $10 / 16-\mathrm{H}$ & $10 / 16-\mathrm{H}$ & - & 一 & - & - \\
\hline
\end{tabular}

$-=$ No data

Table 3 The phenotype of $F_{1}$ seeds of reciprocal crosses among 4 mutant lines

\begin{tabular}{|c|c|c|c|c|c|}
\hline$q$ & d & CM 21 & CM 1787 & CM 1675 & CM 1834 \\
\hline \multicolumn{3}{|c|}{ CM 21 (13b-L) } & - & + & + \\
\hline \multicolumn{2}{|c|}{ CM $1787(57-\mathrm{H})$} & - & & + & + \\
\hline \multicolumn{2}{|c|}{ CM $1675(10 / 13 a-L)$} & + & 10/13a-L & & - \\
\hline \multicolumn{2}{|c|}{ CM $1834(10 / 16-H)$} & $10 / 16-\mathrm{H}$ & $10 / 16-\mathrm{H}$ & 10/16-H & \\
\hline
\end{tabular}

$+=$ Normal type, $-=$ No data. 
Table 4 Segregation of normal and mutant types in $F_{2}$ and $F_{3}$ seeds of the crosses between $C M 1675$ and two mutant lines

\begin{tabular}{|c|c|c|c|c|c|}
\hline \multirow[b]{2}{*}{ Cross combination } & \multicolumn{3}{|c|}{ Segregation in $\mathrm{F}_{2}$ seeds } & \multirow[b]{2}{*}{$\chi^{2}(3: 1)$} & \multirow[b]{2}{*}{ Segregated types in $F_{3}$ seeds } \\
\hline & Normal & Mutant & Total & & \\
\hline$\times \mathrm{CM} 1787$ & 42 & $8 * *$ & 50 & $2 \cdot 16$ & Normal, $57-\mathrm{H}, 10 / 13 \mathrm{a}-\mathrm{L}$ and $57-\mathrm{H}$ \\
\hline
\end{tabular}

* 13b-L type (esp-1), ** 57-H type (esp-2)

to confirm the results obtained by $F_{1}$ seeds, $F_{2}$ and $\mathrm{F}_{3}$ seeds of the combination were analyzed.

The segregation mode in $F_{2}$ and the segregated types in $F_{3}$ seeds from the cross between $C M 1675$ and two mutant lines are shown in table 4 . In $F_{2}$ seeds, the segregation ratio of normal types, and $e s p-1$ and $e s p-2$, respectively, showed a good fit to the expected $3: 1$ ratio. In $F_{3}$ seeds of the two combinations, the parent types of the combination and normal type segregated. The results obtained by $F_{2}$ and $F_{3}$ seeds lend support to the argument that the gene for $10 / 13 \mathrm{a}-\mathrm{L}$ in $\mathrm{CM} 1675$ is located at a different locus from esp-1 and esp-2, hence the gene was designated as esp-3.

The segregation mode in $F_{2}$ seeds and segregated types in $F_{3}$ seeds from the crosses between CM 1834 and three mutant lines are shown in table 5. $F_{2}$ seeds obtained from crosses between $\mathrm{CM}$ 1834 and CM 21 and CM 1675, respectively, indicated only the $10 / 16-\mathrm{H}$ type, while in the cross combination of CM 1834 and CM 1787, the segregation of $10 / 16-\mathrm{H}$ and $10 / 16 / 57-\mathrm{H}$ types showed a good fit to the expected $3: 1$ ratio. In $\mathrm{F}_{3}$ seeds from all combinations, the parent types of the combination and normal type segregated. The results obtained by $F_{2}$ and $F_{3}$ seeds support the fact that the gene for $10 / 16-\mathrm{H}$ is located at a different locus from esp-1 and esp-2. They further indicate that this gene is located at a different locus from esp-3, hence, the gene for $10 / 16-\mathrm{H}$ in $\mathrm{CM}$ 1834 was designated as $E s p-4$.

In table 3, where CM 21 was crossed with the pollen parent, $F_{1}$ seeds of the combinations with CM 1675 indicated normal type, hence, it is assumed that esp-1 is epistatic to the esp-3. This point, however, could not be confirmed in the $F_{2}$ and $F_{3}$ seeds of this study, and remains the subject of future study.

Yamagata and Tanaka (1986) reported that the protein accumulated in PB-I appears to be synthesized by membrane bound polysomes attached to PB-I or the rough endoplasmic reticulum, before they pass through the membrane into the lumen where they are deposited in aggregate form. Of esp-1, esp-3 and Esp-4, which are mutants for PB-I (Kumamaru et al., 1988; Ogawa et al., 1989), esp-1 is controlled by the seed genotype (Kumamaru et al., 1987). By contrast, the present study demonstrated that $e s p-3$ and $E s p-4$ are controlled by the plant genotype. The mechanism governing expression in maternally inherited mutants remains unclear, but the following two points may be tentatively proposed. First, the part of the organelle involved in the synthesis of the storage proteins, such as the membrane, is transmitted from the embryo sac to the endosperm, but degenerates in the embryo. Second, the storage proteins, or their precursors, are synthesized in the plant, shifted into endosperm and accumulated in PB-I. Furthermore, the fact that the proteins which accumulate in PB-I are governed by seed and plant genotypes implies that the system of the genetic control for protein accumulation in PB-I is extremely complex. It is expected that the mechanism of the protein accumulation into PB-I will be elucidated by utilization of the esp-1,esp-3 and Esp-4 mutants.

It is essential to make PB-II increase and/or PB-I decrease for the improvement of the nutritional value of the endosperm. It has been shown

Table 5 Segregation of normal and mutant types in $F_{2}$ and $F_{3}$ seeds of the crosses between $C M 1834$ and three mutant lines

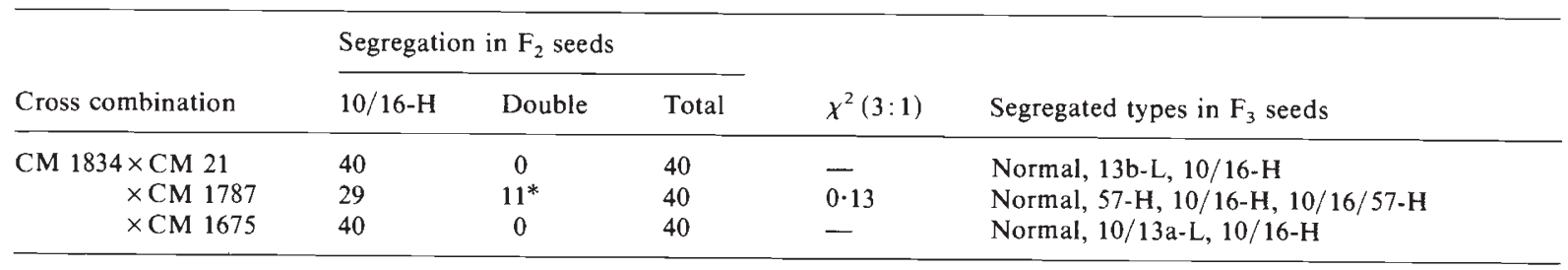

* $10 / 16 / 57-\mathrm{H}$ type. 
that $10 / 13 \mathrm{a}-\mathrm{L}$, which is controlled by esp-3, is a mutant affecting PB-I decrease, and that $10 / 16-\mathrm{H}$, which is controlled by Esp-4, is a mutant causing higher glutelin accumulation in PB-II than in Kinmaze (Kumamaru et al., 1988). However, whether the increase of glutelin is due to the pleiotropism of Esp-4 or to the action of other genes, remains the subject of future study. These mutant lines, once utilized, will no doubt enable qualitative improvement of rice storage proteins.

\section{REFERENCES}

BEACHELl, H. M., KHUSH, G. S. AND JULIANO, B. O. 1972. Breeding for high protein content in rice. In Rice Breeding, Int. Rice Res. Inst., Los Baños, Philippines, pp 419-428.

BURNOUF, T., BOURIQUET, R. AND POUllard, P. 1983. Inheritance of glutenin subunits in $F_{1}$ seeds of reciprocal crosses between european hexaploid wheat cultivars. Theor. Appl. Genet., 64, 103-107.

Dhaliwal, H. S. 1977. Genetic control of seed proteins in wheat. Theor. Appl. Genet., 50, 235-239.

DOLL, H. 1980. A nearly non-functional mutant allele of the storage protein locus Hor2 in barley. Hereditas, 93, 217222.

HIGASHI, T., KUSHIBUCHI, K. AND ITO, R. 1974. Studies on breeding for high protein rice. I. Protein content of different rice varieties and their relations with some agronomic traits including yield (in Japanese with English summary). Jpn. J. Breed., 24, 88-96.

KAMBAYASHI, M., TSURUMI, I. AND SASAhARA, T. 1984. Genetic studies on improvement of protein content in rice grain (in Japanese with English summary). Jpn. J. Breed., 34, 356-363.

KUMAMARU, T., SATOH, H., IWATA, N., OMURA, T. AND OGAWA, M. 1987. Mutants for rice storage proteins. III. Genetic analysis of mutants for storage proteins of protein bodies in the starchy endosperm. Jpn. J. Genet., 62, 333-339.

KUMAMARU, T., SATOH, H., IWATA, N., OMURA, T., OGAWA., M. AND TANAKA, K. 1988. Mutants for rice storage proteins. 1. Screening of mutants for rice storage proteins of protein bodies in the starchy endosperm. Theor. Appl. Genet. 76, 11-16.

LAEMMLI, U. K. 1970. Cleavage of structural proteins during the assembly of the head of bacteriophage T4 Nature, 227, $680-685$.
OGAWA, M., KUMAMARU, T., SATOH, H., IWATA, N., OMURA, T., KASAI, Z. AND TANAKA, K. 1987. Purification of protein body-I of rice seed and its polypeptide composition. Plant Cell Physiol., 28, 1517-1527.

OGAWA, M., KUMAMARU, T., SATOH, H., OMURA, T., PARK, T., SHINTAKU, K. AND BABA, K. 1989. Mutants for rice storage proteins. 2. Isolation and characterization of protein bodies from rice mutants. Theor. Appl. Genet., 78, 305-310.

OSONE, K. AND TAKAGI, T. 1970. Studies on breeding for high protein content and quality in rice. I. Estimation of seedprotein content using the dye-binding method. Jpn. J. Breed., 20, 301-304.

SATOH, H. AND OMURA, T. 1979. Induction of mutation by the treatment of fertilized egg cell with $\mathrm{N}$-methyl-Nnitrosourea in rice. J. Fac. Agr., Kyushu Univ., 24, 165-174.

SHIN, Y. B., TANAKA, S. AND KATAYAMA, T. 1977. Studies on the quantitative and qualitative improvement of rice. Application of $\mathrm{DBC}$ as a screening technique and assessment of Japanese local rice varieties for high protein and lysine (in Japanese with English summary). Sci. Bull. Fac. Agr., Kyushu Univ., 31, 145-150.

SOAVE, C., REGGIANI, R., FONZO, N. D. AND SALAMINI, F. 1981. Clustering of genes for $20 \mathrm{kd}$ zein subunits in the short arm of maize chromosome 7. Genetics, 97, 363-377.

TANAKA, K., SUGIMOTO, T., OGAWA, M. AND KASAI, Z. 1980. Isolation and characterization of two types of protein bodies in the rice endosperm. Agric. Biol. Chem., 44, 16331639.

TANAKA, Y., HAYASHIDA, S. AND HONGO, M. $1975 a$. Quantitative relation between feces protein particles and rice protein bodies (in Japanese with English summary). J. Agric. Chem. Soc. Jpn., 49, 425-429.

TANAKA, Y., HAYASHIDA, S. AND HONGO, M. 1975b. The relationship of the feces protein particles to rice protein bodies. Agric. Biol. Chem., 39, 515-518.

UDA, H. 1923. On "maternal inheritance". Genetics, 8, 322-335.

VAlentini, G., SOAVE, C. AND OtTAVIANO, E. 1979. Chromosomal location of zein genes in Zea mays. Heredity, 42, 33-40.

YAMAGATA, H., SUGIMOTO, T., TANAKA, K. AND KASAI, $Z$. 1982. Biosynthesis of storage proteins in developing rice seeds. Plant Physiol., 70, 1094-1100.

YAMAGATA, H. AND TANAKA, K. 1986. The site of synthesis and accumulation of rice storage proteins. Plant Cell Physiol., 27, 135-145.

YOSHIMURA, Y. 1981. Maternally conditioned mutant for the body color of newly hatched larva in the silkworm (in Japanese). J. Seric. Sci. Jpn., 50, 206-212.

YOSHIMURA, Y. 1985. Linkage studies on the "maternal chocolate" mutant in the silkworm, Bombyx mori (in Japanese). J. Seric. Sci. Jpn., 54, 208-212. 